Quim. Nova, Vol. 36, No. 3, 364-367, 2013

\title{
OTIMIZAÇÃO DA ESTERIFICAÇÃO DE ÁCIDO HEXANÓICO COM $n$-BUTANOL EMPREGANDO LIPASE (Termomyces lanuginosus) IMOBILIZADA EM GELATINA
}

\author{
Everton Skoronski* \\ Departamento de Engenharia Ambiental, Universidade do Estado de Santa Catarina, Av. Luis de Camões, 2090, 88520-000 Lages \\ - SC, Brasil \\ Jair Juarez João, Maria Alice Prado Cechinel e Mylena Fernandes \\ Departamento de Engenharia Química, Universidade do Sul de Santa Catarina, Av. José Acácio Moreira, 787, 88704-900 Tubarão \\ $-\mathrm{SC}$, Brasil
}

Recebido em 20/3/12; aceito em 5/10/12; publicado na web em 18/2/13

\begin{abstract}
OPTIMIZATION OF $n$-BUTYL HEXANOATE SYNTHESIS APPLYING LIPASE IMMOBILIZED (Termomyces Lanuginosus) IN GELATIN. The application of Lipozyme (Termomyces lanuginosus) immobilized in gelatin gel in aliphatic ester synthesis was investigated taking the esterification of hexanoic acid with $n$-butanol as a model reaction. Conditions were optimized by factorial design and the highest conversion was obtained under the following conditions: molar ratio alcohol: acid of 2:1, reaction time of $48 \mathrm{~h}$ and biocatalyst weight of $7.0 \mathrm{~g}$. Under these conditions the esterification yield was around $98 \%$. The operational stability of the immobilized lipase was assessed and results showed that after 12 batch runs, the enzyme showed no significant loss of activity.
\end{abstract}

Keywords: immobilization; lipase; esther synthesis.

\section{INTRODUÇÃO}

Ésteres são importantes compostos orgânicos, obtidos por síntese química, enzimática ou extraídos de alguns produtos, através da utilização de solventes adequados. Dentre suas diversas aplicações, os ésteres de cadeia curta têm destaque como aromatizantes em produtos alimentícios, farmacêuticos e cosméticos. ${ }^{1,2}$

As sínteses de ésteres geralmente são lentas e necessitam da utilização de um catalisador adequado a fim de que se tornem viáveis economicamente. Os processos catalíticos tradicionais envolvem ácidos (como ácido sulfúrico) e bases (como hidróxido de sódio) como aceleradores da reação. ${ }^{3}$ Porém, esses catalisadores têm sido, aos poucos, substituídos por enzimas, visto que essas apresentam como benefícios condições suaves de reação (temperatura, pressão e $\mathrm{pH}$ ), especificidade e estabilidade operacional. ${ }^{4}$

A motivação para a síntese enzimática de ésteres aromatizantes, em solventes orgânicos, está relacionada à alta aceitabilidade comercial, pois caracteriza o produto como natural e é mais específica e viável quando comparada com a produção por via química convencional.,

A utilização de lipases (triacilglicerol acil hidrolases, E.C. 3.1.1.3) provenientes do fungo Thermomyces lanuginosus, comercializadas sob a denominação de Lipozyme TL, tem sido citada em diversos trabalhos relacionados à obtenção de ésteres. ${ }^{1,2,6-13}$

Na sua forma imobilizada, estas enzimas são mais estáveis no meio orgânico, facilitando sua recuperação e posterior reutilização. ${ }^{8}$ Dessa forma, ainda existe um grande campo de estudos a ser explorado, relacionado à síntese enzimática de ésteres em sistemas que empreguem materiais de baixo custo como suportes, gerando resultados que permitam avaliar a viabilidade técnica econômica da produção desses compostos.

Métodos de imobilização utilizando organo-gel têm sido investigados sob o ponto de vista de agregar maior estabilidade para a enzima e também para a aplicação da catálise enzimática em meio orgânico, uma vez que muitos substratos são insolúveis em água. ${ }^{14,15}$

O principal objetivo deste trabalho foi avaliar a atividade da enzima, Lipozyme TL, imobilizada em gel de gelatina, na esterificação

*e-mail: skoronski@cav.udesc.br do ácido hexanoico com $n$-butanol, sendo este composto utilizado como substrato padrão. A partir disto foi realizada uma comparação do desempenho da enzima na síntese de outros ésteres da mesma série.

\section{PARTE EXPERIMENTAL}

\section{Preparação do biocatalisador}

A primeira etapa do trabalho consistiu na preparação do biocatalisador (sistema: organo-gel + enzima). Foram adotadas as seguintes condições, determinadas em ensaios prévios, utilizando as seguintes quantidades de reagentes: $4,5 \mathrm{~mL}$ de água, $3,5 \mathrm{~mL}$ de $n$-hexano, $3 \mathrm{~g}$ de gelatina, $2 \mathrm{~mL}$ de Triton X-100 0,24 mmol/L e 0,5 mL da enzima Lipozyme TL, obtida junto à Novozyme em sua forma livre, com atividade enzimática de $100 \mathrm{KLU} / \mathrm{g}$. $1 \mathrm{LU}$ representa a quantidade de enzima que promove a geração de $1 \mu \mathrm{mol}$ de ácido butírico por minuto, a partir da hidrolise da tributirina em pH 7,0.

\section{Avaliação na síntese de ésteres}

O biocatalisador foi utilizado na reação de esterificação do ácido hexanoico com $n$-butanol e a influência de três fatores - tempo de reação $\left(x_{1}\right)$, massa de catalisador $\left(x_{2}\right)$ e razão molar álcool:ácido $\left(x_{3}\right)$ - foi avaliada sobre a conversão da reação $(Y)$. As reações foram conduzidas em banho-maria tipo Dub-Noff com agitação orbitalar de $30 \mathrm{rpm}$ a $25^{\circ} \mathrm{C}$, em erlenmeyers de $125 \mathrm{~mL}$, alimentados com 30 $\mathrm{mL}$ de solução contendo $0,65 \mathrm{~mol} \mathrm{~L}^{-1}$ de ácido hexanoico e 0,325 mol L ${ }^{-1}$ de $n$-butanol, dissolvidos em $n$-hexano. Para avaliação dos diversos fatores foi adotado um delineamento experimental DCCR, com três fatores do tipo $2^{3}$, dois níveis e inserção de ponto rotacional e repetição do ponto central. Ao todo foram realizados 20 experimentos. Os níveis dos fatores estão apresentados na Tabela 1.

Foi ajustado um modelo matemático de segunda ordem (Equação 1), com o objetivo de representar matematicamente a conversão (Y) obtida em função dos fatores aplicados nos experimentos.

$Y=A_{0}+A_{1} x_{1}+A_{2} x_{1}^{2}+A_{3} x_{2}+A_{4} x_{2}{ }^{2}+A_{5} x_{3}+A_{6} x_{3}{ }^{2}+A_{7} x_{1} x_{2}+$

$A_{8} x_{1} x_{3}+A_{9} x_{2} x_{3}$ 


\section{Avaliação da conversão nas reações de esterificação}

A concentração de ácido carboxílico na reação foi determinada por titulação volumétrica do tipo ácido-base, sendo um indicativo da conversão do ácido em éster ao longo do tempo. Alíquotas de 200 $\mu \mathrm{L}$ foram retiradas do meio reacional a cada $10 \mathrm{~min}$, diluídas para 2 mL com solução alcoólica $96^{\circ} \mathrm{GL}$ e tituladas com solução alcoólica de $\mathrm{KOH} 0,2 \mathrm{~mol} \mathrm{~L}^{-1} \cdot{ }^{16,17}$

A geração do éster no meio reacional foi também determinada qualitativamente por espectroscopia de infravermelho com transformada de Fourier (FTIR), utilizando pastilhas de KBr. A formação de éster pode ser comprovada através do aparecimento de um pico na região de $1738 \mathrm{~cm}^{-1}$, referente ao estiramento do seu grupo carbonila, enquanto que a presença de ácido também está relacionada à presença de carbonila, no entanto, em $1709 \mathrm{~cm}^{-1} .{ }^{18}$ Este procedimento foi realizado em um ensaio onde foram aplicadas as condições otimizadas de esterificação, determinadas nos experimentos anteriormente descritos.

\section{Avaliação da atividade catalítica frente a diversos substratos}

Para a melhor condição experimental, conforme já mencionado, novos ensaios foram realizados, variando-se o tamanho da cadeia carbônica do álcool (metanol, $n$-pentanol e $n$-hexanol) e do doador do grupo acila (ácido fórmico, ácido pentanoico e ácido hexanoico). Os experimentos foram realizados em triplicata e as médias foram comparadas a um nível de significância estatística de $5 \%$ pelo teste de Tukey.

\section{Avaliação da estabilidade operacional do biocatalisador}

Definidas as condições ótimas de imobilização do biocatalisador, foi avaliada a estabilidade operacional frente a vários ciclos de reações, na esterificação do ácido hexanoico pelo $n$-butanol, utilizando $n$-hexano como solvente externo. As reações foram conduzidas em banho-maria tipo Dub-Noff, com agitação orbitalar de $30 \mathrm{rpm}$ a 25 ${ }^{\circ} \mathrm{C}$, em erlenmeyers de $125 \mathrm{~mL}$, alimentados com $2,45 \mathrm{~mL}$ de ácido hexanoico e $0,90 \mathrm{~mL}$ de $n$-butanol dissolvidos em $30 \mathrm{~mL} n$-hexano. O tempo de reação foi fixado em $48 \mathrm{~h}$, bem como a massa de sistema (gelatina + enzima) mantida em 7,0 g.

A enzima imobilizada foi utilizada como biocatalisador em 12 ciclos em batelada consecutivos, com o objetivo de avaliar a sua estabilidade frente ao número de reutilizações. Os experimentos foram realizados em triplicata e as médias foram comparadas a um nível de significância estatística de 5\% pelo teste de Tukey.

\section{Análises estatísticas}

Foi utilizado o software STATISTICA 7.0, (StatSoft, Inc.) como ferramenta para o tratamento de dados resultantes do planejamento experimental e do teste de Tukey.

\section{RESULTADOS E DISCUSSÃO}

\section{Avaliação da aplicação do biocatalisador na síntese de éster}

Para a reação de esterificação foram observadas condições que conduzem a uma maior conversão de éster. Para a razão molar, a relação álcool:ácido de 2:1 (Figuras 2 e 3 ) tende maximizar a conversão molar, assim como o tempo de reação de $48 \mathrm{~h}$ (Figuras 1 e 2) e a massa de biocatalisador (organo-gel + enzima) igual a 7,0 g (Figuras $1 \mathrm{e} \mathrm{3)}$ ).

Avaliando o efeito da massa do biocatalisador e o tempo da reação, observa-se uma tendência para otimização da conversão da reação de esterificação para os valores mencionados anteriormente.

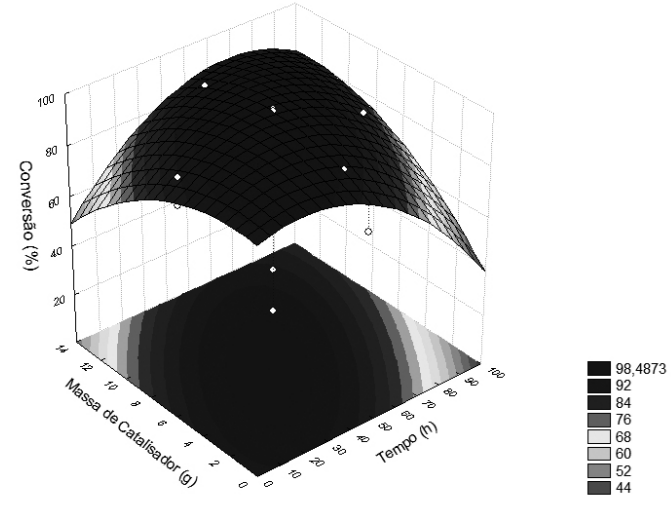

Figura 1. Efeito da massa do biocatalisador e do tempo na conversão da reação para uma razão molar de 2:1 (álcool:ácido)

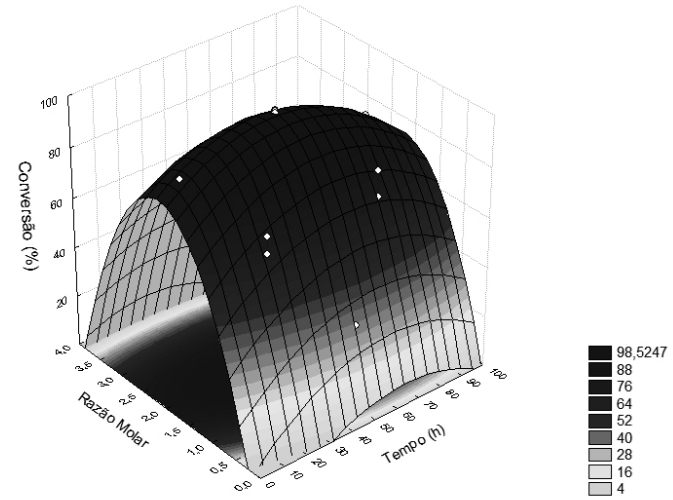

Figura 2. Efeito da razão molar (álcool:ácido) e do tempo na conversão da reação para uma massa de biocatalisador igual a $7 \mathrm{~g}$

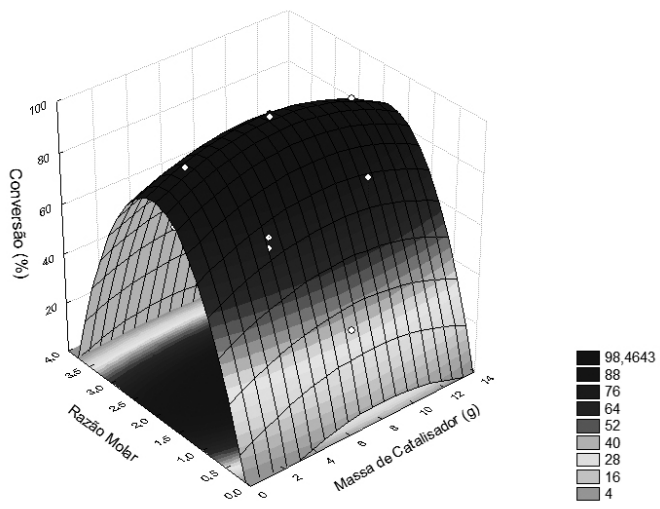

Figura 3. Efeito da massa do biocatalisador e da razão molar (álcool:ácido) na conversão da reação para um tempo $48 \mathrm{~h}$

Para valores de massa de biocatalisador abaixo de $7 \mathrm{~g}$, a pequena quantidade de enzima imobilizada aplicada na reação justifica os menores valores de rendimento para o mesmo tempo de reação. Por outro lado, valores acima de $7 \mathrm{~g}$ implicam em uma maior quantidade de água presente no meio, sendo este presente no biocatalisador, que possui potencial para deslocar a reação de esterificação no sentido de hidrolisar o éster formado (Figura 1).

O efeito de deslocamento da reação no sentido da hidrólise é percebido quando se analisa o fator tempo de reação, utilizando-se a quantidade ótima de biocatalisador no meio reacional. Observa-se que um aumento no tempo de reação favorece o aumento no rendimento da reação de hidrólise, resultando em um efeito global negativo com 
relação à produção de éster (Figuras 1 e 2).

O efeito da razão molar de ácido:álcool também se apresentou como um fator estatisticamente significativo para a conversão destes substratos em éster (Figuras 2 e 3). Uma vez que a conformação espacial do meio é totalmente dependente da polaridade do solvente presente no meio, existe uma combinação adequada de ácido hexanoico e $n$-butanol que favorece um valor de polaridade adequado para a conformação tridimensional da enzima.

A formação do éster foi comprovada com a realização de análises de FT-IR em pastilha de KBr. A Figura 4 apresenta um exemplo de resultado obtido após a realização desta análise. Os picos em destaque, $1736 \mathrm{e} 1709 \mathrm{~cm}^{-1}$, referem-se à presença de éster formado e ácido orgânico residual, respectivamente.

Foi ajustado um modelo matemático (Equação 1) de segunda ordem aos dados obtidos experimentalmente com a aplicação do delineamento experimental, sendo que este apresentou um alto

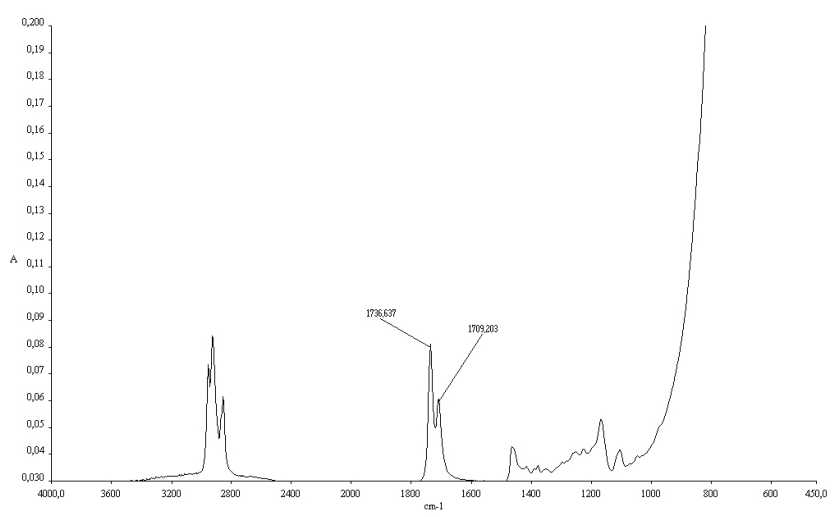

Figura 4. Espectro de FTIR obtido para um determinado instante do avanço da reação. $O$ eixo das abscissas representa o número de onda em $\mathrm{cm}^{-1}$ e o das ordenadas a absorvância coeficiente de correlação $\left(\mathrm{R}^{2}=0,9998\right)$. Os valores preditos pelo modelo encontram-se listados na Tabela 1. Observa-se uma boa concordância entre os valores previstos e aqueles obtidos experimentalmente, viabilizando a utilização desta equação na modelagem dos dados experimentais. Todos os fatores avaliados para a confecção do modelo foram estatisticamente significativos para o modelo em questão, apresentando valores de $\mathrm{p}<0,05$ (Tabela 2).

Este modelo pode ser utilizado para realizar a previsão da conversão da reação através de determinados dados de entrada apresentados, sendo eles a razão molar, a temperatura e a massa de biocatalizador.

\section{Influência da cadeia do éster na atividade catalítica da enzima}

A Tabela 3 apresenta os valores de conversão alcançados na esterificação dos diversos alcoóis e ácidos nas condições otimizadas para a reação modelo (tempo de reação igual a $45 \mathrm{~h}$, massa de biocatalisador igual a 7,0 g e razão molar álcool:ácido de 2:1). Os resultados indicam que conversões mais elevadas foram alcançadas nas reações que envolvem o $n$-pentanol (88,52 e 87,81\%) empregando como doador do grupo acila os ácidos hexanoico e láurico, respectivamente. Uma vez que o peso molecular influencia através de efeito estéreo a interação dos substratos com o sítio ativo da enzima, é de se esperar que determinadas substâncias funcionem como substratos com maior afinidade frente a outros.

Além disto, substratos que apresentam elevada polaridade como o ácido fórmico e o metanol, em todas as situações apresentaram menores rendimentos frente às reações com compostos da mesma série com maior número de átomos de carbono. Desta forma, substratos que apresentam elevada polaridade causam efeito negativo para a atividade catalítica da Lipozyme TL. ${ }^{19}$

\section{Avaliação da estabilidade operacional da enzima}

Os resultados obtidos apontam que após 12 bateladas a enzima

Tabela 1. Valores obtidos experimentalmente após a aplicação do delineamento experimental $2^{3} \mathrm{e}$ valores preditos pelo modelo de segunda ordem. $x_{l}$ é o tempo de reação (h), $x_{2}$ é a massa de catalizador (g) e $x_{3}$ é a razão molar álcool:ácido

\begin{tabular}{|c|c|c|c|c|c|c|c|c|}
\hline \multirow{3}{*}{ Testes } & \multicolumn{6}{|c|}{ Variáveis } & \multirow{2}{*}{\multicolumn{2}{|c|}{ Conversão (\%) }} \\
\hline & \multicolumn{2}{|c|}{$x_{1}$} & \multicolumn{2}{|c|}{$x_{2}$} & \multicolumn{2}{|c|}{$x_{3}$} & & \\
\hline & Real & Codificada & Real & Codificada & Real & Codificada & Observado & Predito \\
\hline 1 & 24 & -1 & 4 & -1 & $1: 1$ & -1 & 71,82 & 72,01 \\
\hline 2 & 72 & +1 & 4 & -1 & $1: 1$ & -1 & 67,71 & 67,90 \\
\hline 3 & 24 & -1 & 10 & +1 & $1: 1$ & -1 & 64,75 & 64,94 \\
\hline 4 & 72 & +1 & 10 & +1 & $1: 1$ & -1 & 77,92 & 78,11 \\
\hline 5 & 24 & -1 & 4 & -1 & $3: 1$ & +1 & 71,44 & 71,63 \\
\hline 6 & 72 & +1 & 4 & -1 & $3: 1$ & +1 & 51,59 & 51,78 \\
\hline 7 & 24 & -1 & 10 & +1 & $3: 1$ & +1 & 60,68 & 60,87 \\
\hline 8 & 72 & +1 & 10 & +1 & $3: 1$ & +1 & 58,10 & 58,30 \\
\hline 9 & 8 & $-1,68$ & 7 & 0 & $2: 1$ & 0 & 87,99 & 87,73 \\
\hline 10 & 88 & $+1,68$ & 7 & 0 & $2: 1$ & 0 & 82,42 & 82,16 \\
\hline 11 & 48 & 0 & 2 & $-1,68$ & $2: 1$ & 0 & 92,17 & 91,91 \\
\hline 12 & 48 & 0 & 12 & $+1,68$ & $2: 1$ & 0 & 91,71 & 91,45 \\
\hline 13 & 48 & 0 & 7 & 0 & $0,32: 1$ & $-1,68$ & 35,29 & 35,03 \\
\hline 14 & 48 & 0 & 7 & 0 & $3,68: 1$ & $+1,68$ & 18,33 & 18,07 \\
\hline 15 & 48 & 0 & 7 & 0 & $2: 1$ & 0 & 98,99 & 98,24 \\
\hline 16 & 48 & 0 & 7 & 0 & $2: 1$ & 0 & 98,10 & 98,24 \\
\hline 17 & 48 & 0 & 7 & 0 & $2: 1$ & 0 & 98,50 & 98,24 \\
\hline 18 & 48 & 0 & 7 & 0 & $2: 1$ & 0 & 97,89 & 98,24 \\
\hline 19 & 48 & 0 & 7 & 0 & $2: 1$ & 0 & 98,00 & 98,24 \\
\hline 20 & 48 & 0 & 7 & 0 & $2: 1$ & 0 & 97,88 & 98,24 \\
\hline
\end{tabular}


Tabela 2. Coeficientes obtidos para o modelo, respectivos valores de p e limite de confiança para um nível de $95 \%$

\begin{tabular}{cccccc}
\hline \multirow{2}{*}{ Coeficiente } & \multirow{2}{*}{ Valor } & \multirow{2}{*}{ Erro padrão } & $\mathrm{p}$ & \multicolumn{2}{c}{ Limites de confiança } \\
\cline { 5 - 6 } & & & & $-95, \%$ & $+95, \%$ \\
\hline$A_{0}$ & $-21,5220$ & 1,422829 & $<0,000001$ & $-24,6923$ & $-18,3518$ \\
$A_{1}$ & 0,6365 & 0,026248 & $<0,000001$ & 0,5780 & 0,6949 \\
$A_{2}$ & $-0,0083$ & 0,000189 & $<0,000001$ & $-0,0087$ & $-0,0079$ \\
$A_{3}$ & 1,3670 & 0,219898 & 0,000099 & 0,8770 & 1,8569 \\
$A_{4}$ & $-0,2626$ & 0,012078 & $<0,000001$ & $-0,2896$ & $-0,2357$ \\
$A_{5}$ & 106,5870 & 0,626069 & $<0,000001$ & 105,1920 & 107,9820 \\
$A_{6}$ & $-25,4018$ & 0,107314 & $<0,000001$ & $-25,6409$ & $-25,1626$ \\
$A_{7}$ & 0,0600 & 0,001999 & $<0,000001$ & 0,0555 & 0,0645 \\
$A_{8}$ & $-0,1640$ & 0,005996 & $<0,000001$ & $-0,1774$ & $-0,1506$ \\
$A_{9}$ & $-0,3080$ & 0,047966 & 0,000076 & $-0,4149$ & $-0,2011$ \\
\hline
\end{tabular}

Tabela 3. Conversões obtidas paras as reações realizadas com diversos substratos na condição otimizada encontrada no trabalho. Foi aplicado o teste de Tukey ao nível de 5\% de probabilidade

\begin{tabular}{ccc}
\hline Ácido & Álcool & Conversão \\
\hline Hexanoico & Pentanol & $88,52 \mathrm{a}$ \\
Hexanoico & Hexanol & $84,94 \mathrm{~b}$ \\
Hexanoico & Metanol & $74,22 \mathrm{e}$ \\
Pentanoico & Pentanol & $82,07 \mathrm{c}$ \\
Pentanoico & Hexanol & $78,49 \mathrm{~d}$ \\
Pentanoico & Metanol & $67,77 \mathrm{f}$ \\
Fórmico & Pentanol & $27,55 \mathrm{~g}$ \\
Fórmico & Hexanol & $19,26 \mathrm{~h}$ \\
Fórmico & Metanol & $5,21 \mathrm{i}$ \\
\hline
\end{tabular}

As médias seguidas pela mesma letra não diferem estatisticamente entre si.

mantém uma boa estabilidade, não apresentando redução estatisticamente significativa na atividade catalítica, para as condições utilizadas neste estudo (Tabela 4). Além disto, não foram observadas mudanças na aparência física do suporte durante a realização do experimento.

Tabela 4. Conversões obtidas para cada batelada. Foi aplicado o teste de Tukey ao nível de $5 \%$ de probabilidade

\begin{tabular}{cc}
\hline Batelada & Conversão média $(\%)$ \\
\hline 1 & $87,61 \mathrm{a}$ \\
2 & $87,63 \mathrm{a}$ \\
3 & $87,57 \mathrm{a}$ \\
4 & $88,19 \mathrm{a}$ \\
5 & $88,05 \mathrm{a}$ \\
6 & $88,29 \mathrm{a}$ \\
7 & $88,53 \mathrm{a}$ \\
8 & $87,81 \mathrm{a}$ \\
9 & $88,77 \mathrm{a}$ \\
10 & $87,33 \mathrm{a}$ \\
11 & $86,99 \mathrm{a}$ \\
12 & $88,08 \mathrm{a}$ \\
\hline
\end{tabular}

As médias seguidas pela mesma letra não diferem estatisticamente entre si.
Esta estabilidade é fundamental para a viabilização do uso destes biocatalisadores em meio reacional, favorecendo a redução de custos para um sistema reacional em escala real.

\section{CONCLUSÃO}

Os resultados obtidos demonstraram que a imobilização de Lipozyme em um sistema organo-gel apresenta boas perspectivas para aplicação em síntese orgânica, principalmente em reações que envolvem a formação de ésteres. O planejamento experimental aplicado foi satisfatório para determinação das condições otimizadas da esterificação do ácido octanoico com $n$-butanol. Além de apresentar boa atividade para o substrato padrão empregado no trabalho, o sistema enzima/organo-gel apresentou baixa atividade catalítica para substratos mais polares. Através deste trabalho pode-se concluir que o sistema empregado para a síntese do hexanoato de butila apresenta boa estabilidade frente a uma série de 12 ciclos de reações em batelada.

\section{AGRADECIMENTOS}

À UNISUL e ao CNPq pelo auxílio financeiro e à Novozymes pelo envio das amostras de enzimas.

\section{REFERÊNCIAS}

1. Gandhi, N. N.; Sawant, S. B.; Joshi, J. B.; Mukesh, D.; Enzyme Microb. Technol. 1995, 17, 373.

2. Abbas, H.; Comeau, L.; Enzyme Microb. Technol. 2003, 32, 589.

3. Morrison, R. T.; Boyd, R. N.; Organic chemistry, $2^{\text {nd }}$ ed., Allyn and Bacon: Boston, 1966.

4. Gabelan, A.; Bioprocess Production of Flavor, Fragance, and Color Ingredientes, Wiley: New York, 1994.

5. Hasan, F.; Shah, A. A.; Hameed, A.; Enzyme Microb. Technol. 2006, 39, 235

6. Freitas, L.; Perez, V. H.; Santos, J. C.; de Castro, H. F.; J. Braz. Chem. Soc. 2007, 18, 1360.

7. Skoronski, E.; Bonetti, T. M.; Joâo, J. J.; Furigo Junior, A.; Ciênc. Tecnol. Aliment. 2010, 30, 897.

8. Dalla Rosa, C.; Oliveira, D.; Oliveira, J. V.; Ciênc. Tecnol. Aliment. 2010, 30, 76.

9. Aragão, V. C.; Anschau, A.; Porciuncula, B. D. A.; Thiesen, C.; Kalil, S. J.; Burkert, C. A. V.; Burkert, J. F. de M.; Quim. Nova 2009, 32, 2268.

10. Rajendrani, A.; Palanisamy, A.; Thangavelu, V.; Brazilian Archives of Biology and Technology 2009, 52, 207.

11. He, W.; Jia, C.; Ma, Y.; Yang, Y.; Zhang, X.; Feng, B.; Yue, L.; J. Mol. Catal. B: Enzym. 2010, 67, 60.

12. Gumel, A. M.; Annuar, M. S. M.; Heidelberg, T.; Chisti, Y.; Process Biochem. 2011, 46, 2079.

13. Dheeman, D. S.; Henehan, G. T. M.; Frías, J. M.; Bioresour. Technol. 2011, 102, 3373.

14. Queiroz, N.; Quim. Nova 1999, 22, 335.

15. Jesus, P. C.; João, J. J.; Silva, P. L. F.; Burlin, G.; Nascimento, M. G.; Quim. Nova 1997, 20, 664.

16. Costa Neto, P. R.; Tese de Doutorado, Universidade Federal de Santa Catarina, Brasil, 2002.

17. de Castro, H. F.; Paula, A. V.; Barboza, J. S.; Quim. Nova 2005, 28, 792.

18. Silverstein, R. M.; Webster, F. X.; Spectrometric identification of organic compounds, John Wiley: New York, 1997.

19. João, J. J.; Zanella, C. R.; Ciência \& Desenvolvimento 2000, 32, 32. 